\title{
Preliminary experiment on a novel photovoltaic-thermoelectric system in summer
}

Guiqiang $\mathrm{Li}^{\mathrm{a}, *}$

Guiqiang.Li@hull.ac.uk

Samson Shittua

(C2020. This manuscript version is made available under the

\section{Kai zhou ${ }^{b}$}

CC-BY-NC-ND 4.0 license http://creativecommons.org/licenses/by-nc-nd/4.0/

\section{Xudong Zhao ${ }^{\mathrm{a}, * *}$}

xudong.zhao@hull.ac.uk

Xiaoli $\mathrm{Ma}^{\mathrm{a}}$

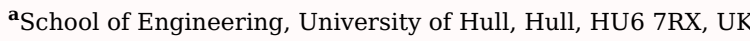

${ }^{\mathbf{b}}$ Department of Mechanical Science and Technology, University of Illinois at Urbana Champaign, 1206 W Green Street Urbana, 61801, Illinois, USA

${ }^{*}$ Corresponding author.

${ }^{* *}$ Corresponding author

Abstract

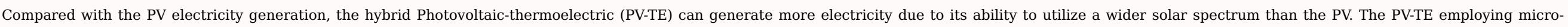

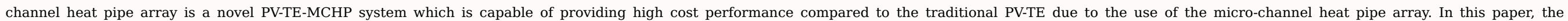

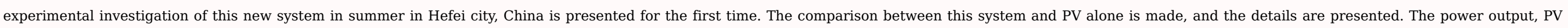

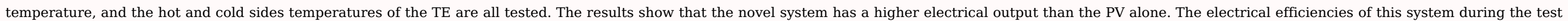

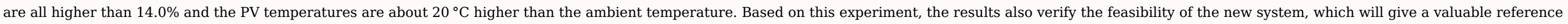
for the PV-TE design.

Keywords: Photovoltaic-thermoelectric; Micro-channel heat pipe; Experimental investigation; Power output

\section{Introduction}

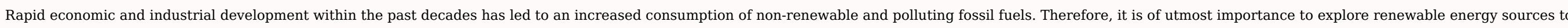

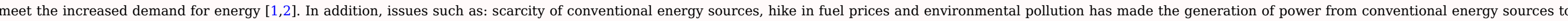

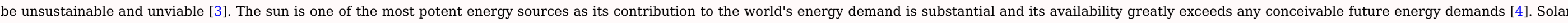

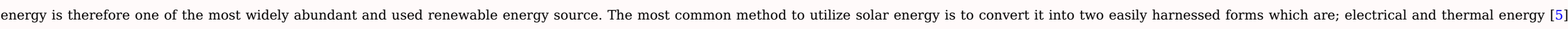

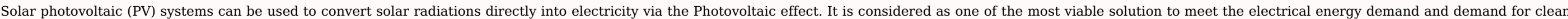

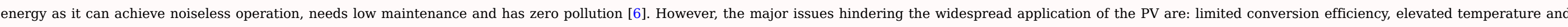
dust accumulation [7].

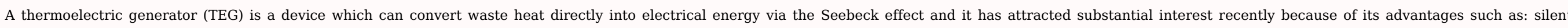

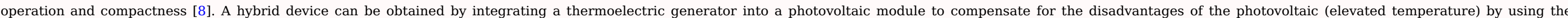




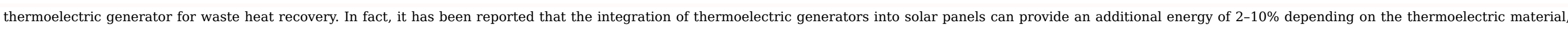

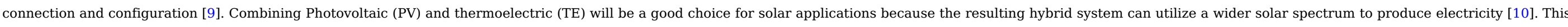
is because, the photovoltaic mainly converts the ultra-violet (UV) and visible regions of the solar spectrum while the thermoelectric utilizes the infrared (IR) region of the solar spectrum [11].

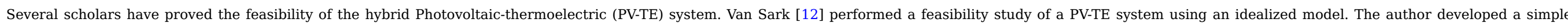

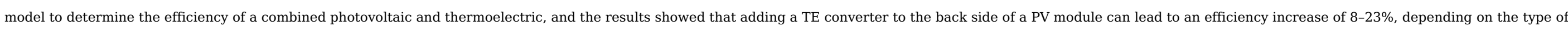

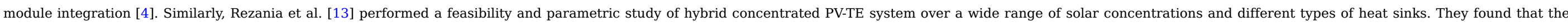

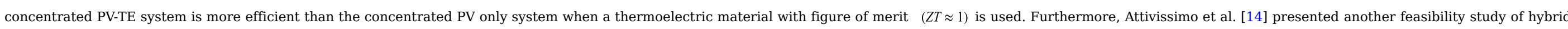
PV-TE systems and the main conclusion from their study is that the PV-TE system performs better when operated in locations with high radiance and low ambient temperature.

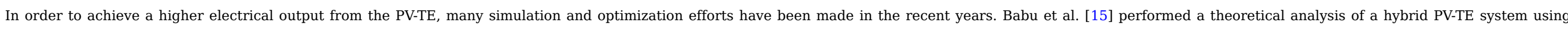

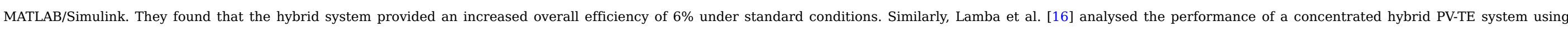

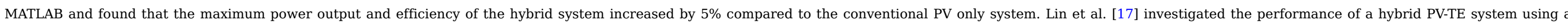

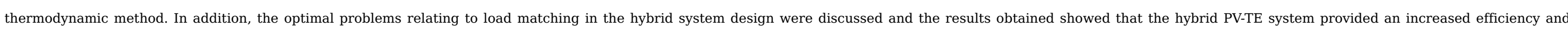

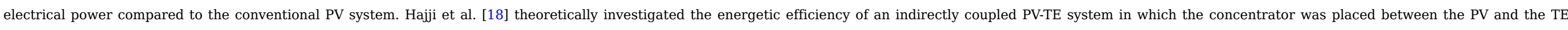

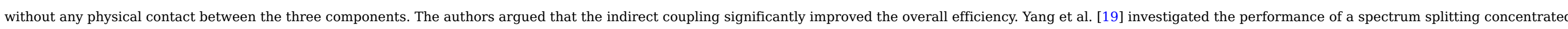

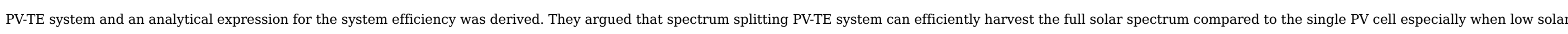

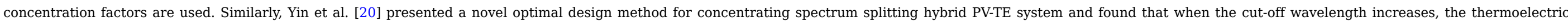
efficiency can be increased through optimization.

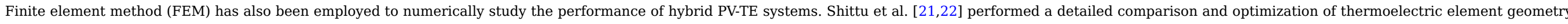

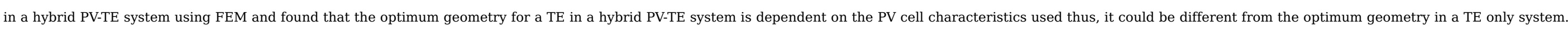

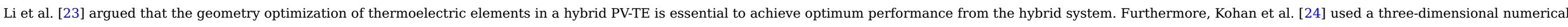

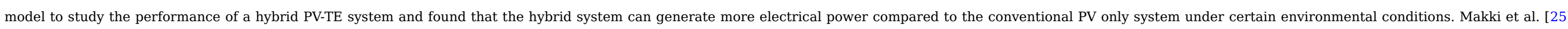

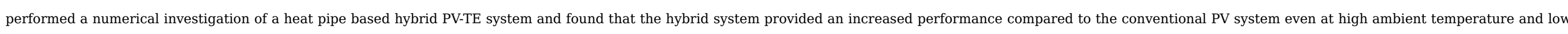

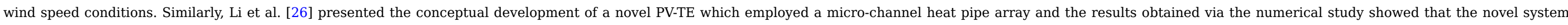
offered a good economic advantage compared to the conventional PV only system.

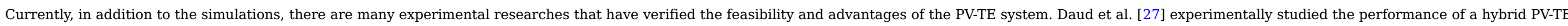

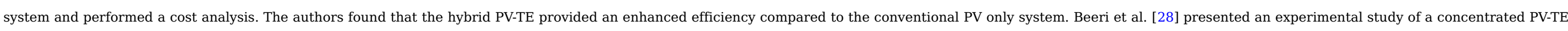

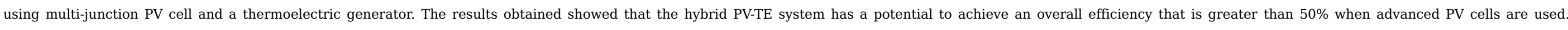

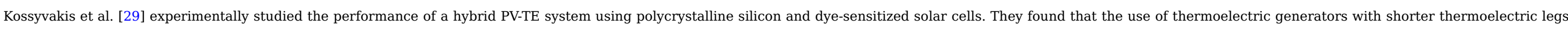

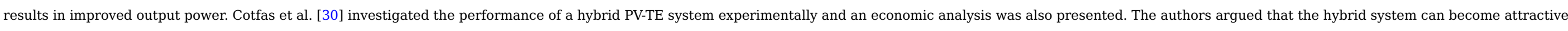

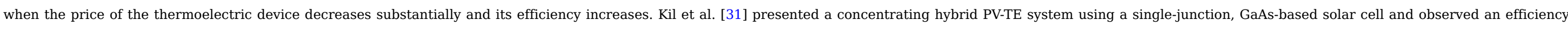

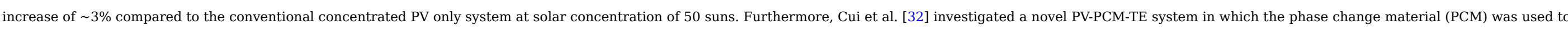

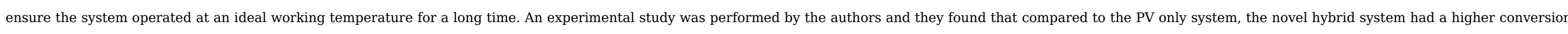

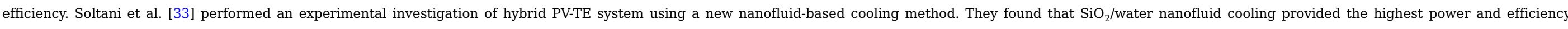

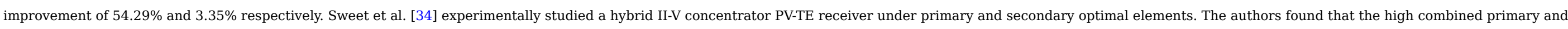

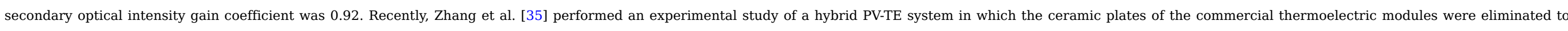
enhance heat transfer and reduce thermal resistance. The authors observed an increase in PV-TE efficiency caused by the V-type groove which was used. 


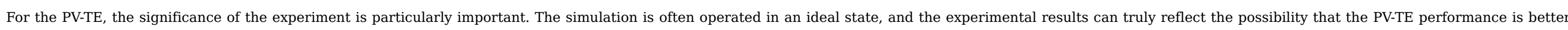

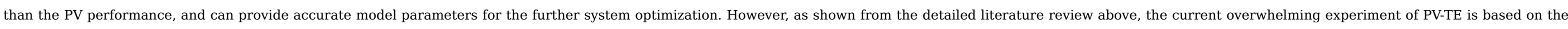

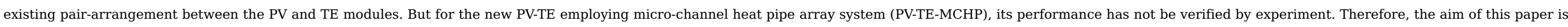
to preliminarily experimentally study the performance of the novel PV-TE-MCHP.

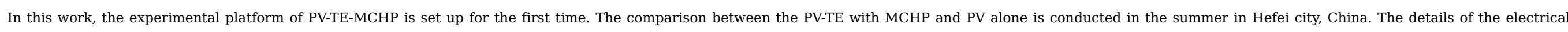

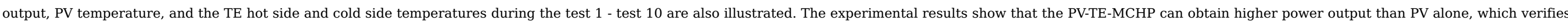
the feasibility of this system.

\section{An experimental set-up}

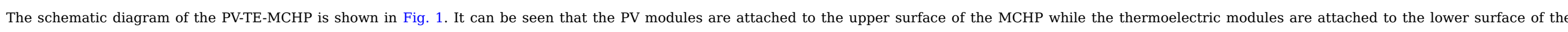

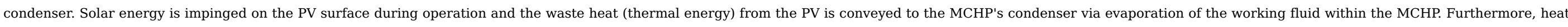

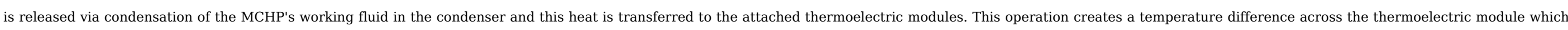

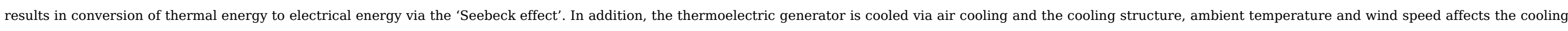
effectiveness.

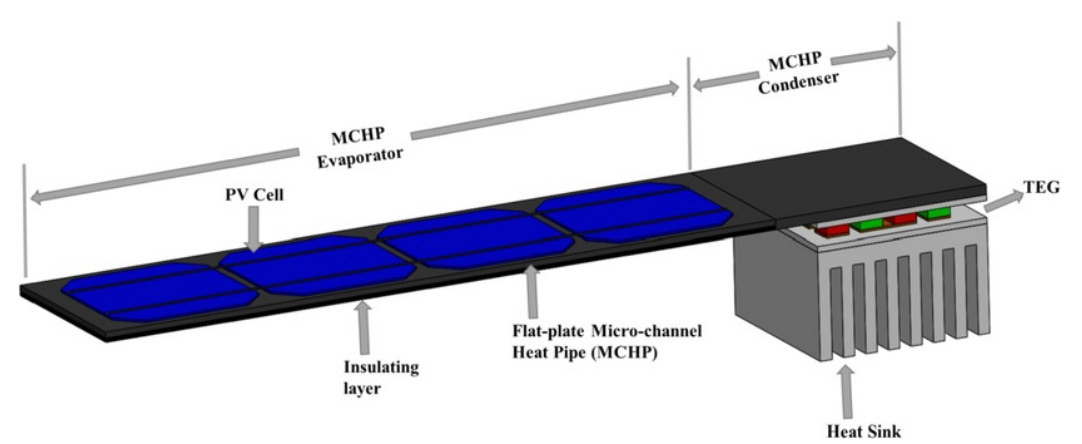

Fig. 1 Schematic diagram of PV-TE-MCHP.

\section{alt-text: Fig. 1}

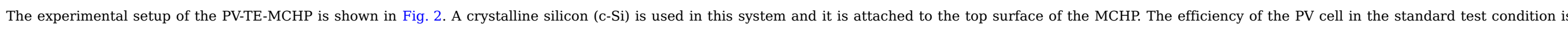

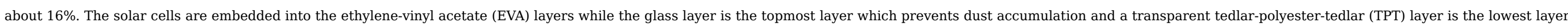

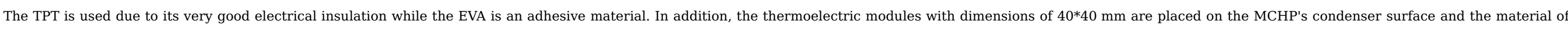

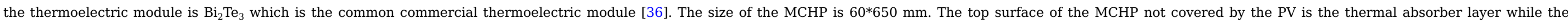

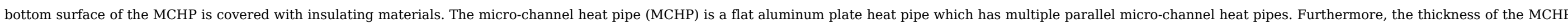

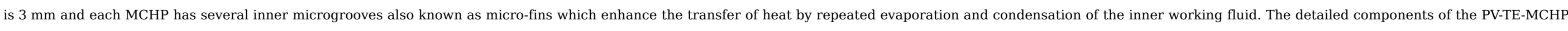
are shown in Table 1.
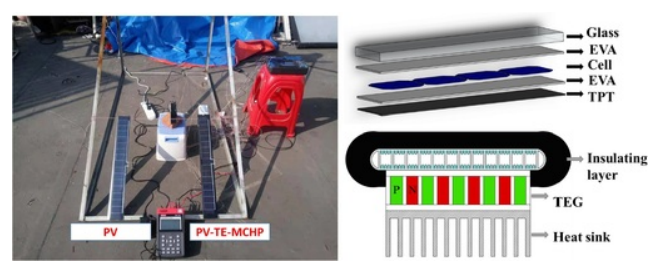


\section{alt-text: Fig. 2}

Table 1 Components of the PV-TE-MCHP system.

alt-text: Table 1

Components

Crystalline silicon

Coverage ratio

MCHP

$$
\text { TEG }
$$

Heat sink
Length of the heat pipe

Width of the heat pipe

$\mathrm{Bi}_{2} \mathrm{Te}_{3}$

Numbers of $\mathrm{P}$ or $\mathrm{N}$ junction nteg

Length of leg

Height of the heat sink $\mathrm{H}$

Length of the heat sink L

Cross section area of the heat sink

Total area of the fins
$6.0 * 6.5^{*} 10^{-3} \mathrm{~m}^{2}$

0.85

$6.5^{*} 10^{-1} \mathrm{~m}$

$6 * 10^{-2} \mathrm{~m}$

$4.0 * 4.0 * 10^{-4} \mathrm{~m}^{2}$

241

$3.4 * 10^{-3} \mathrm{~m}$

$1 * 10^{-2} \mathrm{~m}$

$5 * 10^{-2} \mathrm{~m}$

$1.2^{*} 10^{-4} \mathrm{~m}^{2}$

$1.46^{*} 10^{-2} \mathrm{~m}^{2}$

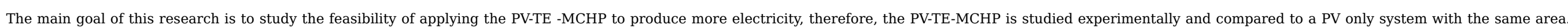

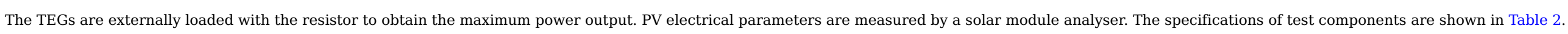

Table 2 The specification of test components.

alt-text: Table 2

\begin{tabular}{|c|c|c|c|c|c|}
\hline Test equipment & Specification & Accuracy & Production site & Quantity & Position \\
\hline Solar Module Analyser & ISM 490 & $\pm 1 \%$ & RS Components Ltd & 1 & Near experimental rig \\
\hline Thermocouple & $0.2 \mathrm{~mm}$ copper-constantan & $\pm 0.5 \mathrm{~K}$ & homemade & 5 & PV surface; TEG hot and cold sides; heat sink surface; \\
\hline Pyranometer & TBQ-2 & $2 \%$ & Jinzhou, China (Sun Co.) & 1 & Near experimental rig with the same surface of the experiment set up \\
\hline Multimeter & Pocket Digital Multimeter & $\pm 1.0 \%$ & Neoteck & 2 & Near experimental rig \\
\hline Ambient monitor & $\mathrm{JZH}-1$ & $\pm 0.5 \mathrm{~K}$ & Jinzhou, China (Sun Co.) & 1 & Near experimental rig \\
\hline
\end{tabular}

Others: Data Acquisition Instrument: Agilent 34970A(USA), test computer, electrical wires, etc.

\section{Experimental procedure and error analysis}

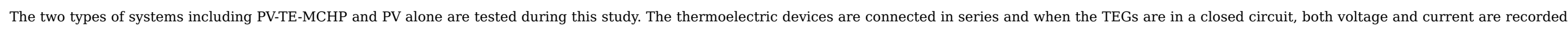

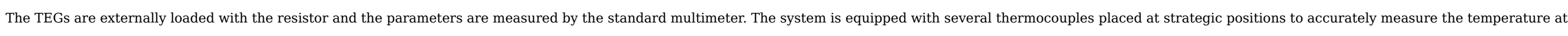

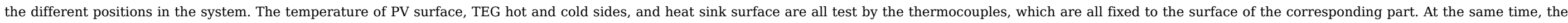


The electrical efficiency of the PV-TE-MCHP can be expressed as

$\eta=\frac{P_{p v}+P_{t e}}{\mathrm{G} \cdot \mathrm{A}}$

where $P_{p V}$ is the PV output, $P_{t e}$ is the TE output.

According to the theory of error propagation, the relative error (RE) of the dependent variable y can be calculated as follows $[37,38]$ :

$R E=\frac{d y}{y}=\frac{\partial f}{\partial x_{1}} \frac{d x_{1}}{y}+\frac{\partial f}{\partial x_{2}} \frac{d x_{2}}{y}+\cdots+\frac{\partial f}{\partial x_{n}} \frac{d x_{n}}{y}$

$y=f\left(x_{1}, x_{2} \cdots x_{n}\right)$

where $x_{i,}(i=1, \ldots, n)$ is the variable of the dependent variable $y . f / x$ is the error transferring coefficient of the variables.

The experimental relative mean error (RME) during the test period can be expressed as:

$R M E=\frac{\sum_{1}^{N}|R E|}{N}$

According to Eq. (2) to Eq. (4), the RMEs of all variables were calculated and the results were given in Table 3.

Table 3 The experimental RME of the variables.

alt-text: Table 3

\begin{tabular}{|c|c|c|c|c|c|c|}
\hline Variable & $T$ & $G$ & $I$ & $U$ & $P$ & $\eta_{\text {power }}$ \\
\hline RME & $0.33 \%$ & $2.0 \%$ & $\pm 1.0 \%$ & $\pm 1.0 \%$ & $2.0 \%$ & $4.0 \%$ \\
\hline
\end{tabular}

\section{Results and discussion}

This study is to compare the electrical outputs between the PV-TE-MCHP system and PV alone. Ten test cases are made and the details of temperatures of the systems are also indicated.

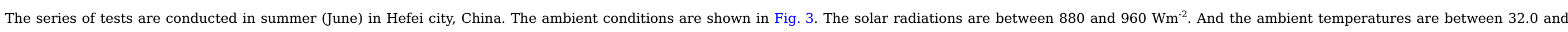
$34.5^{\circ} \mathrm{C}$. The wind speed is between 2.35 and $2.70 \mathrm{~m} / \mathrm{s}$. 


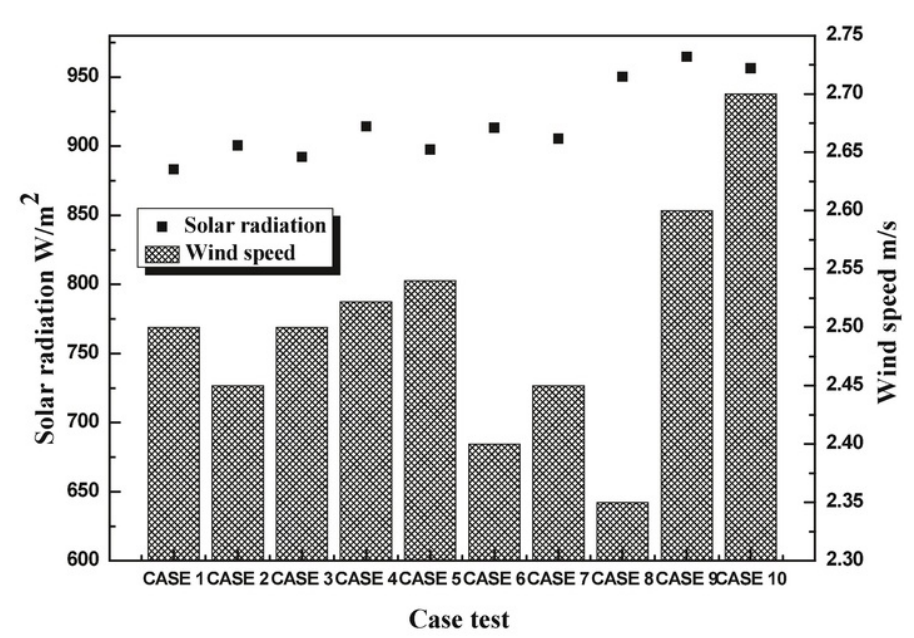

Fig. 3 Ambient conditions of tests.

alt-text: Fig. 3

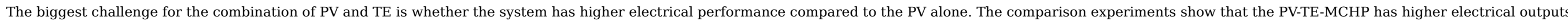

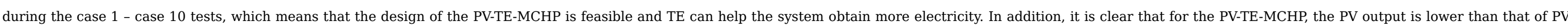

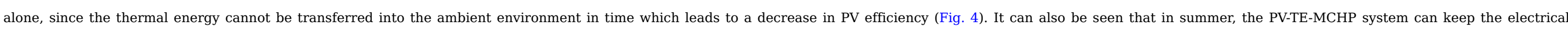

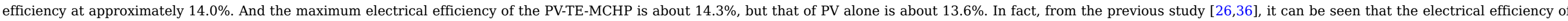

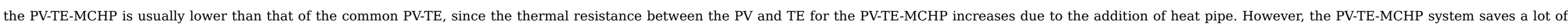
expensive TE devices comparison with the common PV-TE system, so it still has a high cost effective.

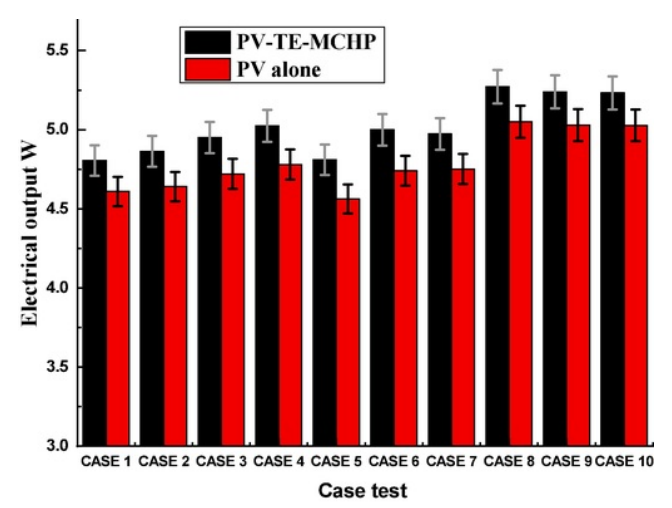

Fig. 4 Electrical output comparison between PV-TE-MCHP and PV alone. alt-text: Fig. 4

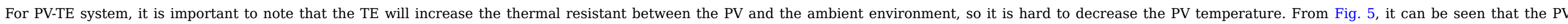

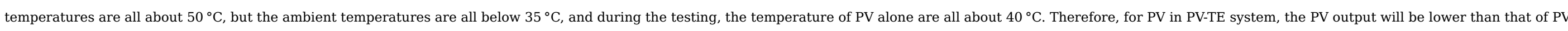
alone, which is the disadvantage of the PV in PV-TE. However, due to the further power production from the TE, the total electrical output will be increased. 


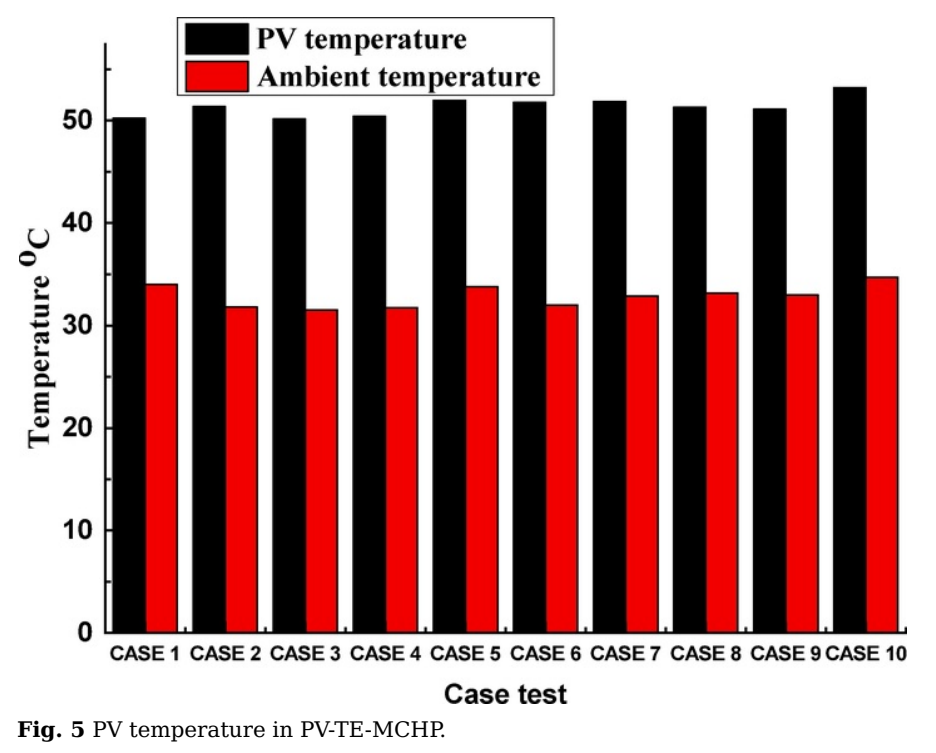

\section{alt-text: Fig. 5}

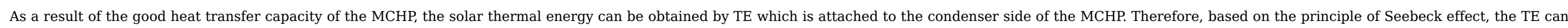

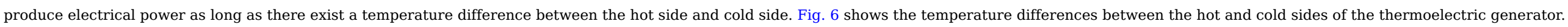

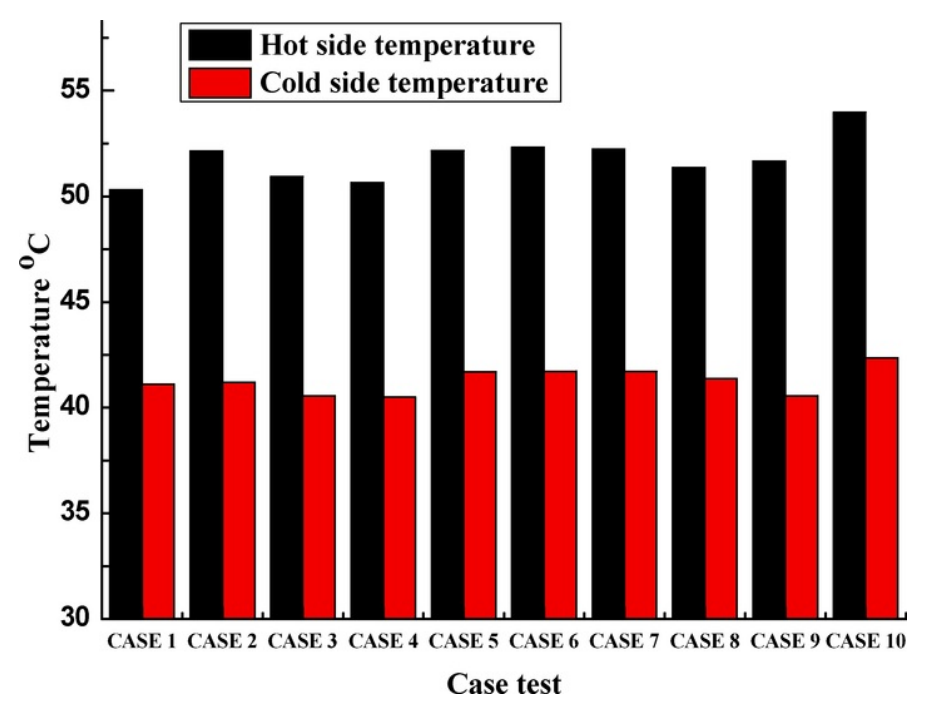

Fig. 6 Hot side and cold side temperatures of TE in PV-TE-MCHP.

alt-text: Fig. 6

\section{Conclusion}

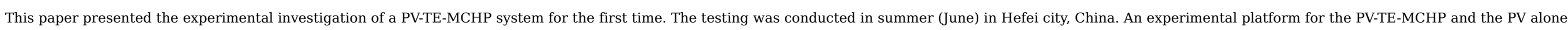


- The PV-TE-MCHP has a higher electrical output than PV alone, and the TE can effectively use the heat transferred by the micro-channel heat pipe to produce more electrical power.

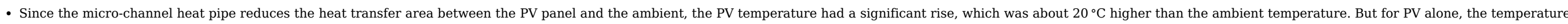
between PV and the ambient is within $10^{\circ} \mathrm{C}$.

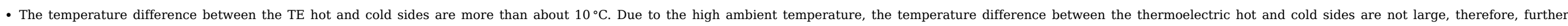
solutions such as increasing the solar radiation, enlarging the PV area and utilizing efficient cooling technology may help to raise the temperature difference.

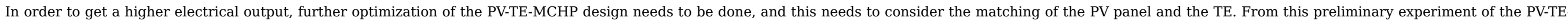

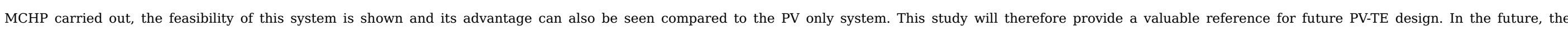
optimization of the components and the system will be carried out to achieve the higher power generation, and the long time testing will be completed.

\section{Acknowledgement}

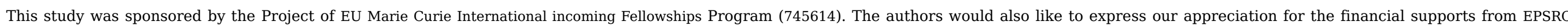

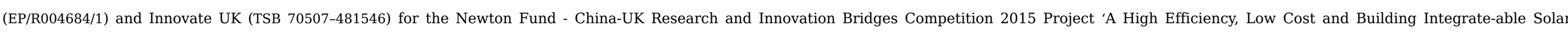
Photovoltaic/Thermal (PV/T) system for Space Heating, Hot Water and Power Supply' and DongGuan Innovation Research Team Program (No. 2014607101008).

\section{References}

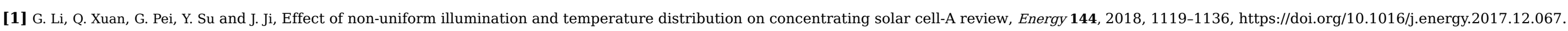

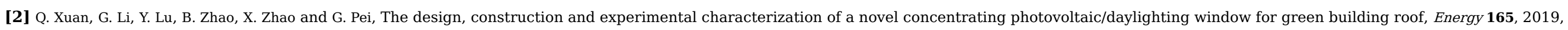
1138-1152, https://doi.org/10.1016/j.energy.2019.03.135.

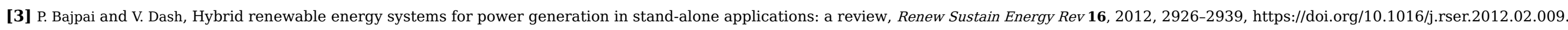

[4] M.S. Guney, Solar power and application methods, Renew Sustain Energy Rev 57, 2016, 776-785, https://doi.org/10.1016/j.rser.2015.12.055.

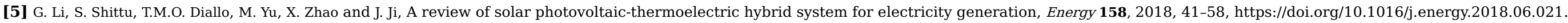

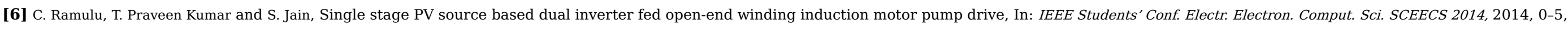
https://doi.org/10.1109/SCEECS.2014.6804459, 2014

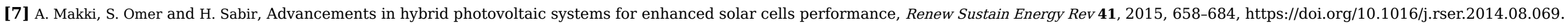

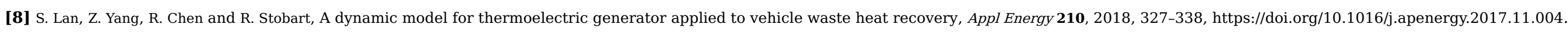

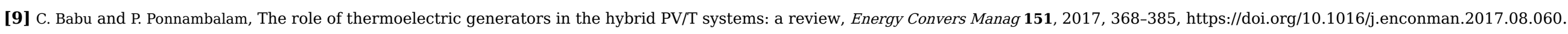

[10] G. Li, K. Zhou, Z. Song, X. Zhao and J. Ji, Inconsistent phenomenon of thermoelectric load resistance for photovoltaic-thermoelectric module, Energy Convers Manag 161, 2018, 155-161, https://doi.org/10.1016/j.enconman.2018.01.079.

[11] P. Huen and W.A. Daoud, Advances in hybrid solar photovoltaic and thermoelectric generators, Renew Sustain Energy Rev 72, 2017, 1295-1302, https://doi.org/10.1016/j.rser.2016.10.042.

[12] W.G.J.H.M. Van Sark, Feasibility of photovoltaic - thermoelectric hybrid modules, Appl Energy 88, 2011, 2785-2790, https://doi.org/10.1016/j.apenergy.2011.02.008.

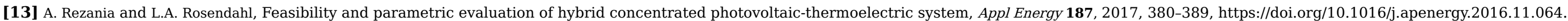


[14] F. Attivissimo, A.M.L. Lanzolla, D. Passaghe, M. Paul, D. Gregory and A. Knox, Photovoltaic-thermoelectric modules: a feasibility study, In: IEEE Instrum. Meas. Technol. Conf., 2014, 659-664, https://doi.org/10.1109/I2MTC.2014.6860825.

[15] C. Babu and P. Ponnambalam, The theoretical performance evaluation of hybrid PV-TEG system, Energy Convers Manag 173, 2018, 450-460, https://doi.org/10.1016/j.enconman.2018.07.104.

[16] R. Lamba and S.C. Kaushik, Solar driven concentrated photovoltaic-thermoelectric hybrid system: numerical analysis and optimization, Energy Convers Manag 170, 2018, 34-49, https://doi.org/10.1016/j.enconman.2018.05.048.

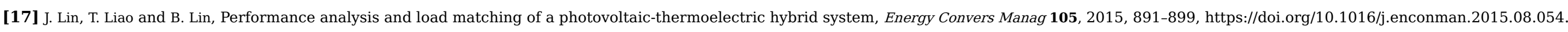

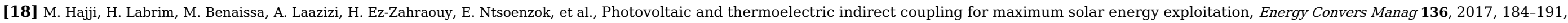
https://doi.org/10.1016/j.enconman.2016.12.088.

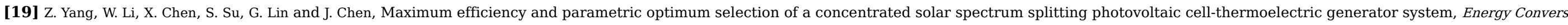
Manag 174, 2018, 65-71, https://doi.org/10.1016/j.enconman.2018.08.038.

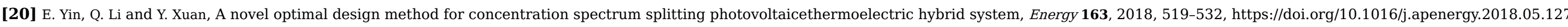

[21] S. Shittu, G. Li, X. Zhao and X. Ma, Series of detail comparison and optimization of thermoelectric element geometry considering the PV effect, Renew Energy 130, 2019, 930-942, https://doi.org/10.1016/j.renene.2018.07.002.

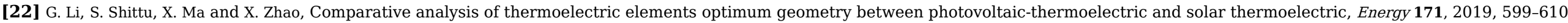
https://doi.org/10.1016/j.energy.2019.01.057.

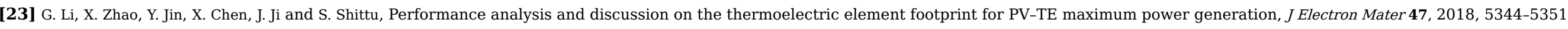
https://doi.org/10.1007/s11664-018-6421-4.

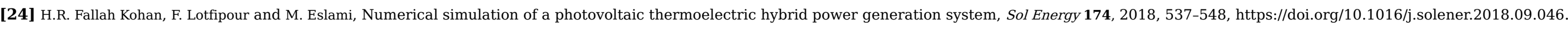

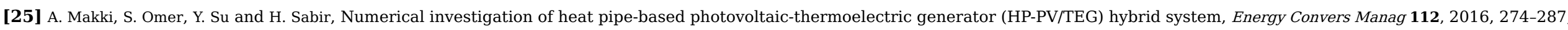
https://doi.org/10.1016/j.enconman.2015.12.069.

[26] G. Li, X. Zhao and J. Ji, Conceptual development of a novel photovoltaic-thermoelectric system and preliminary economic analysis, Energy Convers Manag 126, 2016, 935-943, https://doi.org/10.1016/j.enconman.2016.08.074.

[27] M.M.M. Daud, N.B.M. Nor and T. Ibrahim, Novel hybrid photovoltaic and thermoelectric panel, In: IEEE Int Power Eng Optim Conf PEOCO 2012 - Conf Proc 2012, 2012, 269-274, https://doi.org/10.1109/PEOCO.2012.6230873

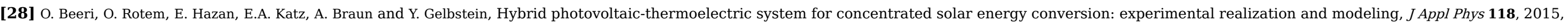
https://doi.org/10.1063/1.4931428.

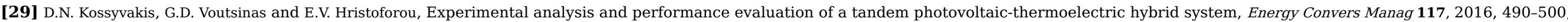
https://doi.org/10.1016/j.enconman.2016.03.023.

[30] D.T. Cotfas, P.A. Cotfas, O.M. Machidon and D. Ciobanu, Investigation of the photovoltaic cell/thermoelectric element hybrid system performance, IOP Conf Ser Mater SCi Eng 133, 2016, 0-10, https://doi.org/10.1088/1757-899X/133/1/012037.

[31] T.-H.H. Kil, S.S. Kim, D.-H.H. Jeong, D.-M.M. Geum, S. Lee, S.-J.J. Jung, et al., A highly-efficient, concentrating-photovoltaic/thermoelectric hybrid generator, Nano Energy 37, 2017, 242-247, https://doi.org/10.1016/j.nanoen.2017.05.023. 
[32] T. Cui, Y. Xuan, E. Yin, Q. Li and D. Li, Experimental investigation on potential of a concentrated photovoltaic-thermoelectric system with phase change materials, Energy 122, 2017, 94-102, https://doi.org/10.1016/j.energy.2017.01.087.

[33] S. Soltani, A. Kasaeian, H. Sarrafha and D. Wen, An experimental investigation of a hybrid photovoltaic/thermoelectric system with nanofluid application, Sol Energy 155, 2017, 1033-1043, https://doi.org/10.1016/j.solener.2017.06.069.

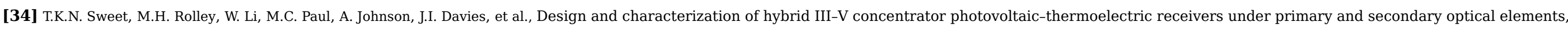
Appl Energy 226, 2018, 772-783, https://doi.org/10.1016/j.apenergy.2018.06.018.

[35] J. Zhang and Y. Xuan, An integrated design of the photovoltaic-thermoelectric hybrid system, Sol Energy 177, 2019, 293-298, https://doi.org/10.1016/j.solener.2018.11.012.

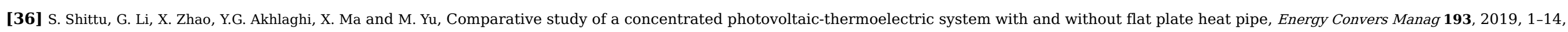
https://doi.org/10.1016/j.enconman.2019.04.055.

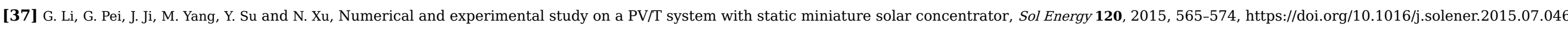

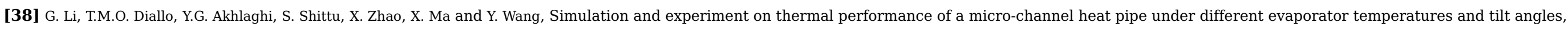
Energy 179, 2019, 549-557, https://doi.org/10.1016/j.energy.2019.05.040.

\section{Nomenclature}

G: solar radiation

I: electric current

$\boldsymbol{U}$ : electric voltage

$T$ : temperature

P: output power

$P_{p V}:$ PV output

$P_{t e}:$ TE output

Greek symbols

$\eta$ : electrical efficiency

\section{Highlights}

- Experiment on a novel Photovoltaic-thermoelectric system in summer was made.

- The comparison between the PV-TE system and PV alone was indicated.

- The PV temperature in PV-TE was about $20^{\circ} \mathrm{C}$ higher than the ambient temperature.

- The maximum electrical efficiency of the PV-TE WAS about $14.3 \%$.

- The PV-TE has a higher electrical output than the PV alone.

\section{Queries and Answers}




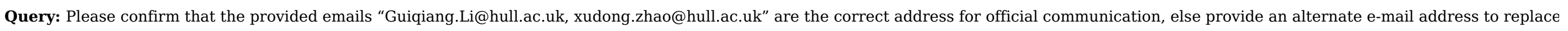
the existing one, because private e-mail addresses should not be used in articles as the address for communication.

Answer: yes.

Query: Have we correctly interpreted the following funding source(s) and country names you cited in your article: TSB, United Kingdom; EPSRC, United Kingdom? Answer: Yes

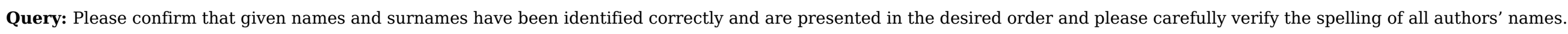
Answer: Yes

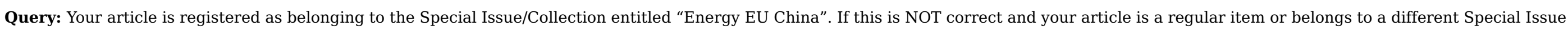
please contact s.venkiteswaran@elsevier.com immediately prior to returning your corrections.

Answer: Yes 